\title{
DESAIN DAN IMPLEMENTASI SISTEM PENENTUAN KEPUTUSAN PRIORITAS HOTEL HALAL DI KOTA BANDUNG DENGAN METODE FUZZY LOGIC MAMDANI
}

\author{
Rizky Fajar Ramdhani \\ Teknik Industri ,STT Wastukancana Purwakarta \\ Jl. Alternative Bukit Indah - Purwakarta, Mulyamekar, Kec. Babakancikao, Kabupaten Purwakarta, Jawa Barat \\ 41151 \\ rizky@stt-wastukancana.ac.id
}

\begin{abstract}
Abstrak
Abstrak : Wisata halal merupakan salah satu trend global saat ini. Pembangunan sektor ini secara terus menerus dilakukan oleh banyak negara termasuk pemerintah Indonesia. indonesia merupakan negara dengan penduduk muslim terbesar di dunia, pemerintah tidak ingin Indonesia hanya menjadi pasar, tetapi juga menjadi pemain yang signifikan. Khususnya Dinas Pemerintah Kota Bandung yang terus membenahi sektor pariwisata dalam hal akomodasi. Penelitian dilakukan di kota Bandung yang memiliki berbagai macam tempat menarik. Penelitian ini bertujuan untuk menentukan urutan hotel berdasarkan kriteria hotel halal. Ukuran variabel dalam survei meliputi produk, layanan, dan pengelolaan berdasarkan Peraturan Menteri Pariwisata dan Ekonomi Kreatif (Permenparekraf) no. 2 tentang implementasi ekonomi syariah yaitu hilal 1. Dengan metode logika fuzzy mamdani akan sangat membantu dalam menentukan pemilihan hotel bagi para pelaku pariwisata. Perhitungan pengolahan data menggunakan software Microsoft Excel. Software MATLAB dengan Fuzzy Logic Toolbox digunakan untuk analisis menggunakan logika fuzzy.
\end{abstract}

Kata kunci: Hotel, Mamdani Fuzzy Logic, Produk, pelayanan, pengelolaan

\begin{abstract}
Halal tourism is one of the global trends today. Many countries carry out the continuous development of this sector. However, including the Indonesian government as the country with the largest Muslim population globally, the government does not want Indonesia to become a market and become a significant player. Especially the Bandung City Government Office, which continues to improve the tourism sector in terms of accommodation. The research is conducting in the city of Bandung, which has various exciting places. This study aimed to determine the order of hotels based on the criteria for halal hotels. The survey variables include product, service, and management based on Permenparekraf no. 2 concerning the implementation of sharia economics, namely the hilal 1. The Mamdani fuzzy logic method will be very helpful in determining hotel selection for tourism actors. Calculation of data processing using Microsoft Excel software. MATLAB software with the Fuzzy Logic Toolbox is using for analysis using fuzzy logic.
\end{abstract}

Keywords: Hotels, Mamdani Fuzzy Logic, Products, Services, Management.

\section{PENDAHULUAN}

Berdasarkan GMTI tahun 2019 akhirnya Indonesia menduduki peringkat pertama wisata halal dunia bersanding dengan Malaysia, dengan total Skor 78, urutan ketiga diraih Turki (Skor 72), dan keempat diraih Arab Saudi (skor 72), posisi kelima oleh Uni Emirat arab (Skor71).

Menurut (Aan Jaelani, 2017) Istilah wisata halal dalam literatur pada umumnya disamakan dengan beberapa istilah seperti Islamic tourism, syari'ah tourism, halal travel, halal friendly tourism destination, Muslim-friendly travel destinations, halal lifestyle, dan lain-lain. Dari sisi industri, wisata syariah merupakan suatu produk.. pelengkap. dan tidak menghilangkan jenis pariwisata konvensional. Sebagai cara baru untuk mengembangkan pariwisata Indonesia yang menjunjung tinggi budaya dan nilai-nilai Islami tanpa menghilangkan 
keunikan dan orisinalitas daerah (Razzaq, 2016).

Pariwisata halal ialah penyediaan produk dan jasa wisata yang sesuai dengan hukum islam yang diperuntukkan untuk konsumen meliputi perjalanan halal, restoran halal dan hotel halal. Hotel ialah akomodasi yang memberikan pelayanan berupa jasa kamar, menyediakan jasa makanan dan minuman serta akomodasi yang dikelola secara komersil (Chookaew, 2015).

Penerapan Parwisata halal memerlukan suatu metode yang dapat memilih prioritas paling tinggi dalam pemilihan hotel, restaurant, transportasi dan tempat wisata halal. Fuzzy Logic atau logika fuzzy adalah metode yang cocok dalam pemecahan masalah serta solusi permasalahan yang timbul dalam industri pariwista yang memiliki karakteristik unik, Fuzzy Logic menyediakan cara yang sederhana untuk menggambarkan kesimpulan pasti atau tegas dari informasi yang ambigu, samar-samar, atau tidak tepat (Sri Kusuma dewi, 2013). Seperti membantu dalam pemilihan prioritas hotel halal di Kota Bandung yang masih minim dibantu dengan kriteria hilal 1 menurut Peraturan Menteri Pariwisata dan Ekonomi Kreatif, Republik Indonesia Tentang Pedoman Penyelenggaraan Usaha Hotel Syariah Pedoman Penyelenggaraan Usaha Hotel Syariah Nomor 2 Tahun 2014.

Berdasarkan latar belakang tersebut, maka peneliti merumuskan masalah sebagai berikut : Bagaimana penentuan urutan-urutan pilihan hotel sesuai kriteria hotel standarisasi halal produk/jasa di Kota bandung? Kemudian perlukah adanya rekomendasi/usulan hotel yang sesuai dengan kriteria halal? Jika perlu, penulis akan merancang rekomendasi prioritas halal dengan bantuan aplikasi MATLAB.

Tujuan dari penelitian ini adalah menentukan pemilihan hotel berdasarkan penerapan kriteria-kriteria halal 1 hotelhotel di Kota Bandung serta mengimplementasikan sistem pengambilan keputusan hotel dengan MATLAB.

\section{METODE PENELITIAN}

Unit observasi dan lokasi penelitian ini ialah Hotel wilayah kota Bandung. Objek penelitian yaitu hotel dan restoran di Bandung. Pendekatan penelitian dalam penelitian ini adalah menggunakan pendekatan kuantitatif. Penelitian ini untuk mengetahui prioritas hotel halal yang ada di Bandung. Metode yang digunakan penulis ialah menggunakan metode fuzzy logic.

Dalam penyeleksian penentuan hotel yang sesuai dengan kriteria yang diinginkan ini akan menggunakan metode mamdani dengan metode Center of Gravity (CoG) diperlukan kriteria-kriteria dan bobot untuk melakukan perhitungannya sehingga akan didapat alternative terbaik. Adapun Populasi penelitian ini meliputi seluruh pelaku dalam pariwisata halal kota Bandung.

Sampel dalam penelitian ini menggunakan sampling acak Sekitar 30 hotel dan 30 restoran, yang berarti peneliti akan menggunakan sebagian jumlah hotel dan restoran kota Bandung yang akan dijadikan sebagai sampel dalam penelitian ini.

Untuk menentukan sampel dari populasi digunakan perhitungan maupun acuan tabel yang dikembangkan para ahli menurut Roscoe (1975). Secara umum, jumlah sampel minimal penelitian korelasional untuk memperoleh hasil yang baik adalah 30 , dan penelitian eksperimen jumlah sampel minimun adalah 15 dari setiap kelompok. Penelitian survey jumlah sampel minimum adalah 100.

Berikut hotel - hotel yang penulis teliti yang berada di kawasan Kota Bandung :

1. Cinnamon Hotel Boutique Syariah

2. Noor Hotel

3. Ruby Hotel Syariah

4. Grand tjokro Hotel

5. Lingga Hotel

6. Narapati Indah Syariah Hotel

7. Daarul Jannah Cottage

8. Savoy Homan Hotel

9. Grand Preanger

10. The Papandayan Hotel 
11. Grand Pasundan

12. ASTON Braga Hotel

13. Sheraton hotel

14. Trans Hotel

15. Grand Tebu Hotel

16. Tebu Hotel

17. Marbella suites Hotel

18. BTC Hotel

19. IBIS Hotel

20. Grand Serela

21. Galeri ciumbuleuit

22. Luxton Dago Hotel

23. GH Universal Hotel

24. Grand setiabudhi Hotel

25. Green Forest Resort

26. Haris Hotel

27. Clove garden hotel

28. El Royal Hotel

29. Tripple seven Hotel

30. 88 Hotel

Analisis pendekatan dalam penelitian ini menggunakan metode logika Fuzzy yang diperkenalkan oleh Mamdani dan Assilian, pada 1975. Operasi dari sistem pakar ada 4 tahapan dalam inferensi mamdani termasuk juga pada metode yang digunakan oleh Tsukamoto dan Sugeno, tahapan-tahapannya tersebut adalah :

1. Pembentukan Pembentukan himpunan fuzzy (fuzzyfication)

Variabel input dan output terbagi menjadi satu atau lebih himpunan fuzzy.

2. Penerapan fungsi implikasi yang digunakan adalah fungsi imlplikasi MIN

3. Komposisi atau (penggabungan) aturan Inferensi diperoleh dari kumpulan dan korelasi antar aturan terdapat 3 macam: MAX, ADDITIVE, dan probabilistic OR (probor)

4. Penegasan (defuzzification), input berupa suatu himpunan fuzzy yang diperoleh dari komposisi aturan fuzzy, output berupa nilai tegas (crisp). Metode defuzzyfikasi dengan cara centroid atau CoG ( Center of Gravity).
HASIL DAN PEMBAHASAN

Tabel 1. Hasil Output Fuzzy Hotel dengan Metode CoG

\begin{tabular}{|c|c|c|c|}
\hline No & Nama & Skor & $\operatorname{cog}$ fuzy \\
\hline 1 & $\begin{array}{l}\text { Cinnamon Hotel } \\
\text { Boutique Syariah }\end{array}$ & 91,33 & 82,9 \\
\hline 2 & Noor Hotel & 91,33 & 82,9 \\
\hline 3 & Ruby Hotel Syariah & 91,33 & 82,9 \\
\hline 4 & Grand tjokro Hotel & 89,11 & 82,9 \\
\hline 5 & Lingga Hotel & 89,11 & 82,9 \\
\hline 6 & $\begin{array}{l}\text { Narapati Indah Syariah } \\
\text { Hotel }\end{array}$ & 89,11 & 82,9 \\
\hline 7 & Daarul Jannah Cottage & 84,67 & 82,9 \\
\hline 8 & Savoy Homan Hotel & 84,67 & 82,9 \\
\hline 9 & Grand Preanger & 80,67 & 82,9 \\
\hline 10 & The Papandayan Hotel & 80,67 & 82,9 \\
\hline 11 & Grand Pasundan & 79,56 & 82,9 \\
\hline 12 & ASTON Braga Hotel & 79,56 & 82,9 \\
\hline 13 & Sheraton hotel & 79,56 & 82,9 \\
\hline 14 & Trans Hotel & 83,33 & 82,9 \\
\hline 15 & Grand Tebu Hotel & 78,44 & 82,9 \\
\hline 16 & Tebu Hotel & 78,44 & 82,9 \\
\hline 17 & Marbella suites Hotel & 77,11 & 79,6 \\
\hline 18 & BTC Hotel & 70,22 & 75,4 \\
\hline 19 & IBIS Hotel & 68,89 & 75,4 \\
\hline 20 & Grand Serela & 65,11 & 68,7 \\
\hline 21 & Galeri ciumbuleuit & 74,22 & 65,5 \\
\hline 22 & Luxton Dago Hotel & 71,78 & 65,4 \\
\hline 23 & GH Universal Hotel & 66,67 & 65,3 \\
\hline 24 & Grand setiabudhi Hotel & 66,67 & 65,3 \\
\hline 25 & Green Forest Resort & 66,67 & 65,3 \\
\hline 26 & Haris Hotel & 62,44 & 61,3 \\
\hline 27 & Clove garden hotel & 65,78 & 60,8 \\
\hline 28 & 88 Hotel & 62,22 & 59,3 \\
\hline 29 & El Royal Hotel & 62,22 & 59,3 \\
\hline 30 & Tripple seven Hotel & 74,44 & 50,0 \\
\hline
\end{tabular}

Berdasarkan CoG didapatkan hasil CoG Fuzzy dari program MATLAB untuk Hitek dalam Tabel 1 hasil perhitungan CoG fuzzy hotel. Terdapat 16 hoteldengan nilai CoG paling tinggi dengan nilai 82,9 $\%$ diikuti oleh diikuti oleh Marbella Suites Hotel dengan nilai 79,6\%, BTC dan IBIS hotel dengan nilai $\mathrm{CoG} 75,4 \%$, Grand Serela dengan nilai $68,7 \%$, Galeri ciumbuleuit dengan nilai $65,5 \%$, Luxton Dago Hotel dengan nilai 65,4\%, GH Universal Hotel, Grand Setiabudhi, Green Forest Resort dengan nilai 65,3\%. 
Selanjutnya Haris Hotel dengan nilai $61,3 \%$, Clove Garden dengan nilai $60,8 \%$, EL Royal Hotel dan 88 hotel 59,3 dan Tripple Seven Hotel dengan nilai 50\%.

Prioritas pertama (P1) didapatkan karena hotel dan restoran tersebut memperhatikan sangat baik dalam aspek produk, pelayanan dan pengelolaan. Prioritas kedua (P2) didapatkan karena hotel tersebut memperhatikan baik dalam aspek produk, pelayanan dan pengelolaan dan prioritas ketiga (P3) sesuai standar yag ditetapkan.

Tiga buah nilai tegas (crisp) dari input Produk, Pelayanan dan Pengelolaan digunakan sebagai input pada proses fuzzifikasi untuk menghasilkan fuzzy input sesuai dengan membership function input yang dibuat. Hasil proses fuzzifikasi tersebut kemudian digunakan sebagai input pada proses evaluasi rule, untuk menghasilkan fuzzy output, sesuai dengan rule yang telah ditentukan. Selanjutnya fuzzy output akan diinputkan pada proses defuzzifikasi untuk menghasilkan crisp output, dalam hal ini adalah nilai Halal Hotel di Bandung.

\section{Pembentukan Himpunan Fuzzy (fuzzyfication)}

Pembentukan himpunan fuzzy variabel input maupun output dibagi menjadi satu atau lebih himpunan. Berikut ini merupakan Fuzzy Interference System (FIS) yang akan dibuat didalam penelitian ini terdapat tiga input variabel hotel meliputi : produk, pelayanan dan pengelolaan, sedangkan outputnya yaitu Hotel Halal terdapat pada tabel 2 .

Tabel 2. Pembentukan Himpunan Fuzzy

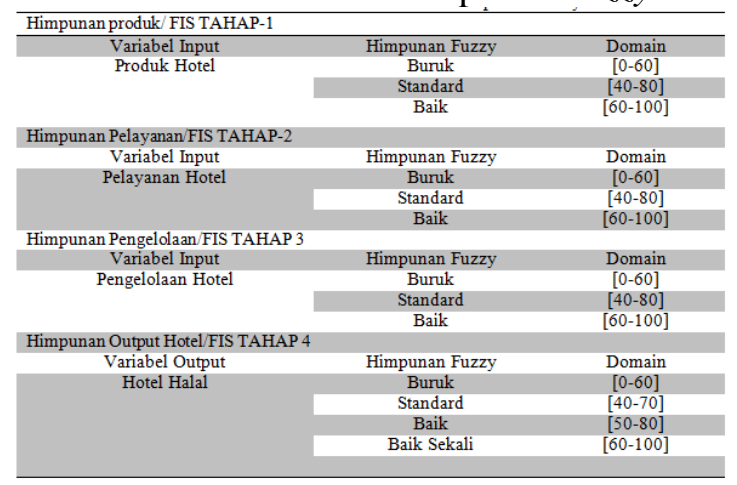

Input fuzzy berupa bilangan crisp (tegas) yang dinyatakan dalam himpunan input. Fuzzifikasi merupakan proses untuk mengubah bilangan crisp menjadi nilai keanggotaan dalam himpunan fuzzy. Fungsi keanggotaan himpunan fuzzy Dapat dilihat pada Gambar 1.

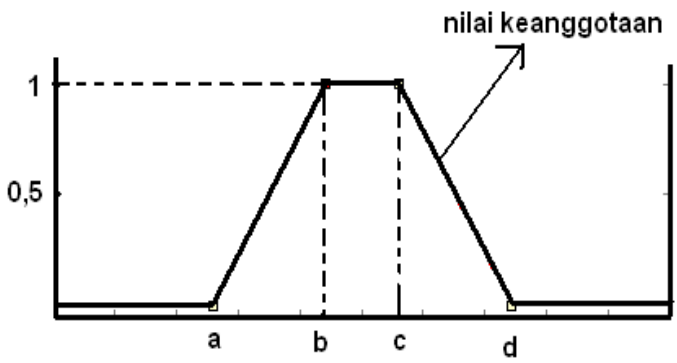

Gambar 1 Fungsi Keanggotaan Himpunan Fuzzy

Pada penelitian menggunakan fungsi keanggotaan trapesium, diwakilkan oleh parameter $\{a, b, c, d\} \quad$ yang didefinisikan sebagai berikut:

$\operatorname{trapesium}(x, a, b, c, d)=\left\{\begin{array}{cc}0, & x \leq a \\ \frac{x-a}{b-a}, & a \leq x \leq b \\ 1, & b \leq x \leq c \\ \frac{d-x}{d-c}, & c \leq x \leq d \\ 0, & d \leq x\end{array}\right.$

- Fungsi keanggotaan untuk nilai input buruk sebagai berikut:

Trapesium $(\mathrm{x}, 0,0,50,60)$ maka

$0, \mathrm{x} \leq 0$

$$
\begin{aligned}
& 1,0 \leq \mathrm{x} \leq 50 \\
& \frac{60-x}{60-50}, 50 \leq \mathrm{x} \leq 60
\end{aligned}
$$

- Fungsi keanggotaan untuk nilai input standar:

Trapesium $(\mathrm{x}, 40,50,70,80)$ maka 0 , $\mathrm{x} \leq 40$

$$
\begin{aligned}
& \frac{x-40}{50-40}, 42 \leq \mathrm{x} \leq 50 \\
& 1,50 \leq \mathrm{x} \leq 70 \\
& \frac{80-x}{80-70}, 70 \leq \mathrm{x} \leq 80
\end{aligned}
$$

- Fungsi keanggotaan untuk nilai input baik:

Trapesium $(\mathrm{x}, 60,70,100,100)$ maka

$0, \mathrm{x} \leq 60$

$$
\frac{x-60}{60-70}, 60 \leq \mathrm{x} \leq 100
$$


Berdasarkan perhitungan fungsi keanggotaan tahap selanjutnya adalah membuat FIS variabel input yang ditunjukan oleh warna kuning. Himpunan fuzzy terdiri dari tiga yaitu Buruk, Standard dan Baik. Tampilan FIS variabel input pada software Matlab pada Gambar 2.

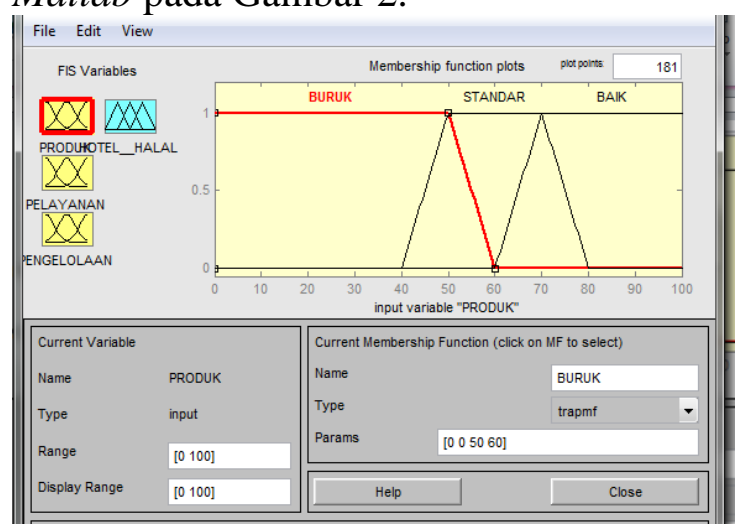

Gambar 2 Tampilan FIS Variabel Input pada Software Matlab

\section{Pembentukan Rule Fuzzy}

Pada penelitian yang saya gunakan menggunakan operasi himpunan irisan (intersection). Implikasi merupakan rules fuzzy untuk dapat menghasilkan output dari setiap rule logika fuzzy logic. Berikut bentuk umum rule/aturan yang digunakan dalam fungsi implikasi:

\section{IF $x$ is A, THEN $y$ is $B$}

Menentukan aturan implikasi, dibuat beberapa aturan untuk dapat membuat output fuzzy, terdapat pada Tabel 3.

Tabel 3. Aturan Pembentukan Implikasi

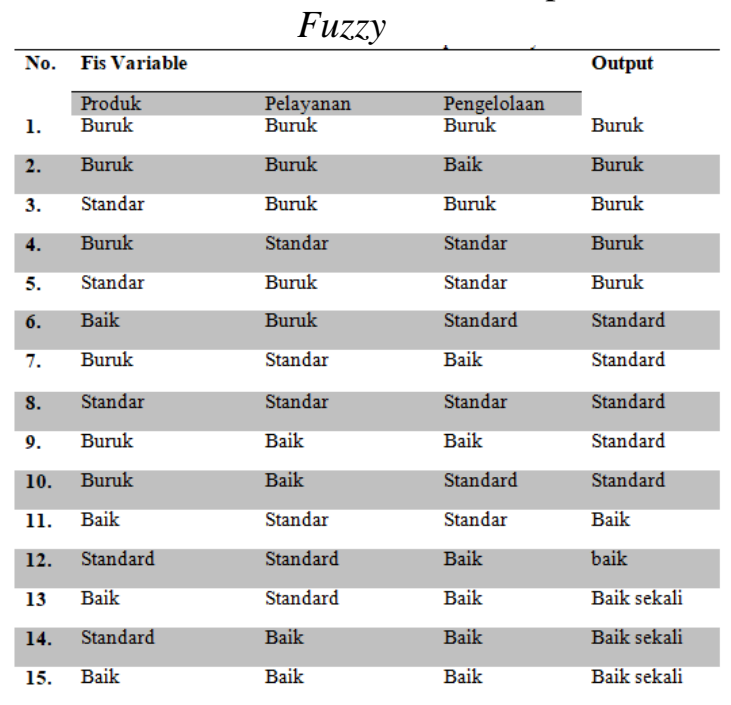

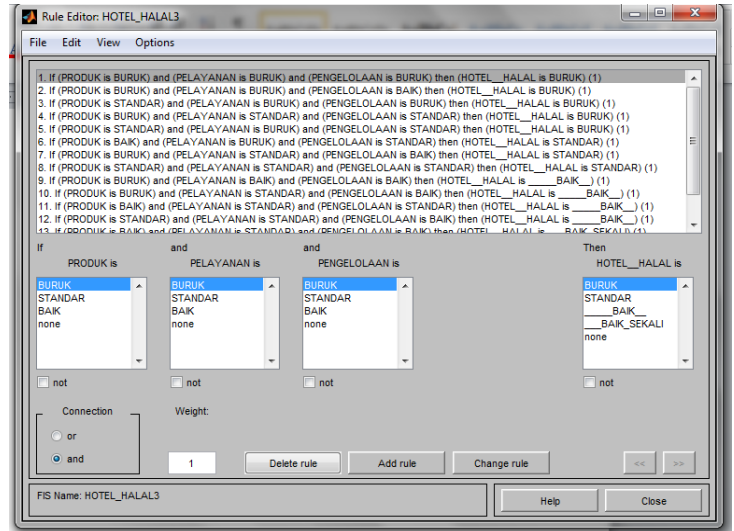

Gambar 3 Rule Fuzzy Logic

\section{Komposisi Penggabungan}

Himpunan fuzzy dapat dioperasikan dengan beberapa macam. Peneliti menggunakan mode operasi intersection dengan basis ekspresi operator minimum $\mu_{\mathrm{a} \cap \mathrm{b}}(\mathrm{u})=\min \left\{\mu_{\mathrm{A}}(\mathrm{u}), \mu_{\mathrm{B}}(\mathrm{u})\right\}$, dengan dasar logika AND

$$
\mu_{\mathrm{a} \cap \mathrm{b}}(\mathrm{u})=\min \left\{\mu_{\mathrm{A}}(\mathrm{u}), \mu_{\mathrm{B}}(\mathrm{u})\right\}
$$

- Fungsi keanggotaan untuk nilai output buruk:

Trapesium $(\mathrm{x}, 0,0,50,6$

0) maka $0, \mathrm{x} \leq 0$

$1,0 \leq \mathrm{x} \leq 50$

$$
\frac{60-x}{60-50}, 50 \leq \mathrm{x} \leq 60
$$

- Fungsi keanggotaan untuk nilai output standar:

Trapesium

$(\mathrm{x}, 40,50,60,70)$

maka $0, x \leq 40$

$\frac{x-40}{50-40}, 40 \leq \mathrm{x} \leq 50$

$1,50 \leq \mathrm{x} \leq 60$

$\frac{70-x}{70-60}, 70 \leq \mathrm{x} \leq 70$

- Fungsi keanggotaan untuk nilai output baik:

Trapesium

$(\mathrm{x}, 50,60,70,80)$

maka $0, x \leq 50$

$\frac{x-50}{60-50}, 50 \leq x \leq 60$

$1,60 \leq \mathrm{x} \leq 70$

$\frac{80-x}{80-70}, 70 \leq \mathrm{x} \leq 80$

- Fungsi keanggotaan untuk nilai output sangat baik: 


$$
\begin{aligned}
& \text { Trapesium } \\
& (\mathrm{x}, 60,70,100,100) \\
& \text { maka } 0, \mathrm{x} \leq 60 \\
& \frac{x-60}{60-70}, 60 \leq \mathrm{x} \leq 70 \\
& 1,70 \leq \mathrm{x} \leq 100
\end{aligned}
$$

Berdasarkan fungsi keanggotaan digunakan untuk membuat FIS variabel output yang ditunjukan oleh warna biru. Himpunan fuzzy terdiri dari empat yaitu Buruk, Standar, Baik dan Baik sekali. Berikut ini merupakan tampilan FIS variabel output pada software Matlab dapat dilihat pada Gambar 4.

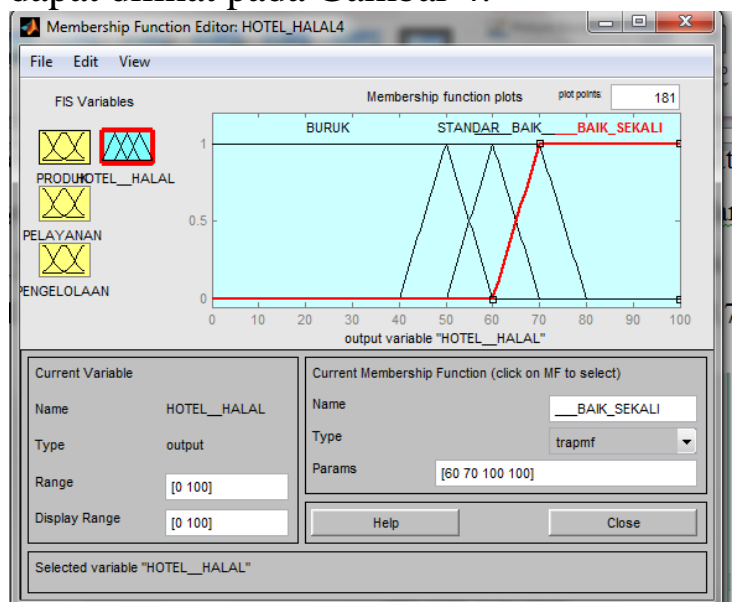

Gambar 4 Tampilan Fis Variabel Output pada Software Matlab

Menentukan output himpunan fuzzy dengan cara perhitungan Central of Gravity dengan rumus Sebagai Berikut :

$\mathrm{COG}=\sum \frac{\mu * \mathrm{x}}{\mu}$

Keterangan:

$\mathrm{CoG}=$ Central of Gravity

$\mathrm{x}=$ Nilai membership function

$\mu=$ nilai fuzzy(a member of fuzzy)

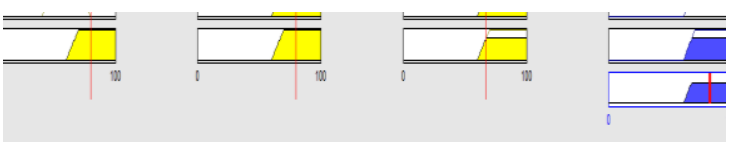

Gambar 5 Defuzifikasi Output Fuzzy Logic

$\mathbf{C o G}=\frac{0.5 *(0+10+20+30+40+50) * 0+(60+70+80+90+100) * 0.5}{0+0+0+0+0+0+0.5+0.5+0.5+0.5+0.5}=80$

Jadi diperoleh Prioritas Baik Sekali hotel di Garut adalah skor 80.

\section{KESIMPULAN}

Dengan metode fuzzy logic dapat membantu dalam penentuan rekomendasi pemilihanprioritas hotel dan restoran bagi para pelaku wisata dari Kriteria variabel halal, penelitian tersebut meliputi produk, pelayanan dan pengelolaan. Maka penelitian ini dapat di ambil kesimpulan sebagai berikut:

1. Metode Fuzzy Logic dapat digunakan untuk pemilihan prioritas Hotel dan di Kota Bandung.

2. Berdasarkan dari hasil penelitian, prioritas urutan-urutan Hotel dirancang dengan menggunakan metode fuzzy logic didapatkan perancangan usulan/rekomendasi berupa rangking Hotel halal tourism yang dapat diterapkan di Kota Bandung menggunakan aplikasi Matlab.

\section{DAFTAR PUSTAKA}

Diskominfo., 2019. 5 Tahun Kembangkan Pariwisata Halal,Indonesia Akhirnya Raih Peringkat Pertama. [online] diskominfo. Tersedia pada: http://diskominfo.go.id/asp/ [Diakses 1 Desember 2019].

Dini Andriani, et al. (2015). Laporan Awal Kajian Pengembangan Wisata Syari'ah.Jakarta: Kementerian Pariwisata RI.

Aan, Jaelani., 2017. Halal tourism industry in Indonesia: Potential and prospects, [e-journal] 20, Tersedia pada website, $<$ https://mpra.ub.unimuenchen.de/76237/1/MPRA_paper_7 6237.pdf> [Diakses 1 Januari 2018].

Razzaq, $\quad$ S., Hall, $\quad$ C.M., $\quad$ dan Prayag, G., 2016. The Capacity of New Zealand to Accommodate The Halal Tourism Market. Tourism Management Perspectives (18) 
Chookaew, S., Chanin, O., Charatarawat, J., Sriprasert, P., \& Nimpaya, S. (2015). Increasing Halal Tourism Potential at Andaman Gulf in. Journal of Economics,

Sri Kusuma dewi, Hari Purnomo, "Aplikasi Logika Fuzzy Untuk Mendukung Keputusan”, Edisi dua, Graha Ilmu, Yogyakarta 2013

Nomer 2 Tahun 2014 Peraturan Menteri Pariwisata dan Ekonomi Kreatif, Republik Indonesia Tentang Pedoman Penyelenggaraan Usaha Hotel Syariah.

Sugiono.2014.Metode Penelitian Kuantitatif dan kualitatif dan R\&D.Bandung Alfabeta.

Roscoe, 1975, dikutip dari Uma Sekaran, 2006, Metode Penelitian Bisnis,Salemba Empat, Jakarta.

Agus, T. 2014. Studi Perbandingan Metode Fuzzy Tsukamoto dan Fuzzy Mamdani untuk Seleksi Pegawai Teladan pada PT. Gracia Pharmindo, h,646

Evan, R., 2015. Fuzzy Logic Modeling untuk pengambilan keputusan menggunakan MATLAB, [e- journal] 33 (30), Tersedia pada: website, 